\title{
MDs to follow conscience on physician-assisted death: CMA annual meeting highlights
}

$\mathrm{M}$ edical marijuana and seniors' care were extensively debated at the Canadian Medical Association (CMA) 147th annual meeting in Ottawa Aug. 17-20, but physicianassisted death was the main action item.

The 269 delegates voted to "support the right of all physicians, within the bounds of existing legislation, to follow their conscience when deciding whether to provide medical aid in dying." That resolution, which was approved by $91 \%$ of delegates, will now be considered by CMA's Board of Directors.

CMA's 2007 policy states that doctors should not participate in euthanasia or assisted suicide. The new position prepares physicians for the possibility that laws may be changing in light of a recent Quebec bill and an upcoming case at the Supreme Court of Canada.

In a related move, delegates asked CMA to develop a strategy to ensure there are enough doctors trained in palliative care.

The annual meeting began with the release of a survey and a call for a national seniors' health care strategy. The survey of 1000 Canadians (aged 45 and older) found that $95 \%$ saw the need for a pan-Canadian seniors' care strategy - a percentage outgoing CMA President Louis Hugo Francescutti called "astonishing." "Federal politicians should worry about this if they want to stay federal politicians," he told CMAJ.

CMA's new president, Dr. Chris Simpson from Kingston, Ont., said the failure to address seniors' needs "impacts every single component of the health care system." For example, "warehousing of seniors in hospital beds" wastes about $\$ 2.3$ billion annually.

In his inaugural address, Simpson also slammed the federal government for its inaction on medicare. He cited a recent report from the Commonwealth Fund indicating that Canada's health system ranks second last on virtually every measure of quality and access. Topranked countries all have "strong leadership" from a committed federal government. He urged the federal government

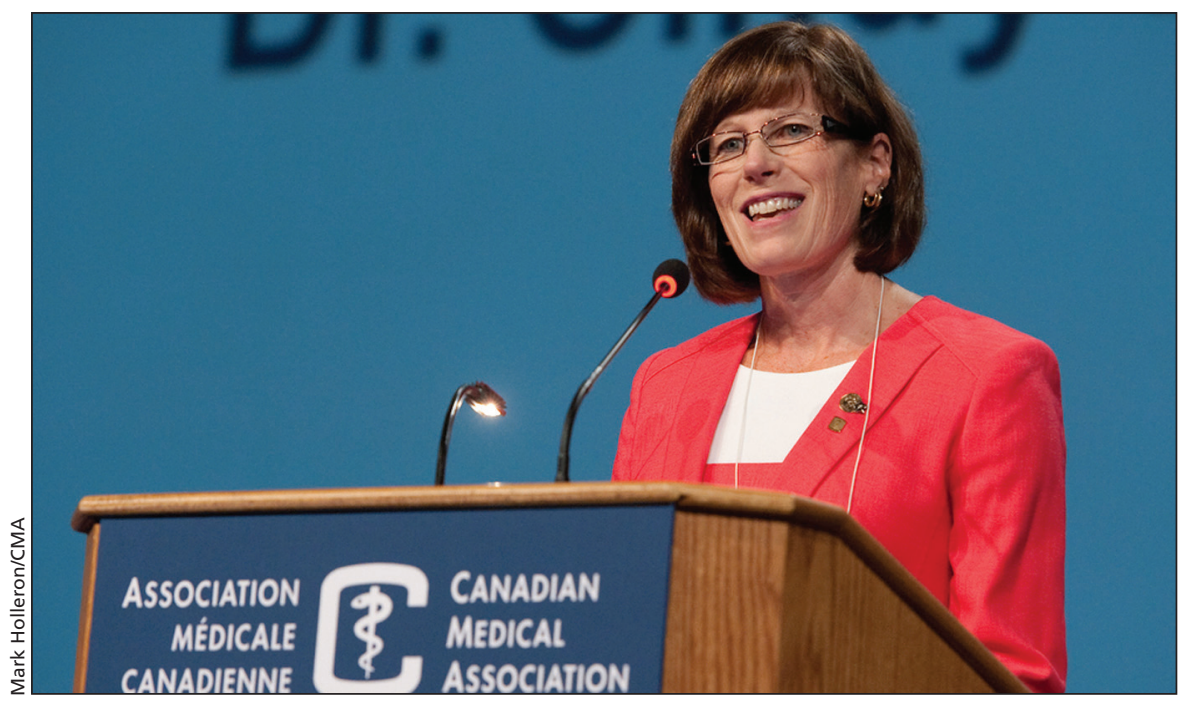

Among the highlights of the 2014 CMA annual meeting was the confirmation of Presidentelect Dr. Cindy Forbes of Nova Scotia.

to begin with a comprehensive seniors care strategy.

Federal Health Minister Rona Ambrose said a national strategy is "valid" but so far there has been no call from the provinces or territories to create one.

Ambrose also responded to concerns about Canada's new medical marijuana law, which puts physicians in a "precarious situation." "The majority of doctors don't want to prescribe and I would encourage them not to do it if they don't want to," she said. At the same time, she insisted that doctors are the best gatekeepers for marijuana.

Francescutti said the new law, which came into effect Apr. 1, 2014, "strains the physician-patient relationship."

"It's just plain bad medicine to prescribe a product when we don't know how it works ... or how much to prescribe."

The CMA's long-standing position is that there is insufficient evidence supporting marijuana's use as a therapeutic agent. Delegates approved a motion calling for the CMA to speak out against smoking any plant material. Respirologist Dr. Deborah Hellyer noted that smoking one joint is the equivalent of up to 10 cigarettes.

A second motion called for licensing bodies to develop comprehensive regu- latory standards to guide physicians in prescribing marijuana. Currently the information available and policies vary.

\section{New president elect}

Delegates confirmed the election of CMA President-elect Dr. Cindy Forbes, from Waverley, Nova Scotia. Her term as president begins Aug. 2015. Forbes has practised as a family physician for 28 years and is the former president of Doctors Nova Scotia (1996/97).

"My goal as president is to identify and promote innovative solutions and positive change for health care," she stated in a media release. She identified seniors' care and the health care transformation initiative as two areas of engagement.

During the meeting, CMA received the Canadian Forces Medallion for Distinguished Service. It recognizes CMA's long support for the Forces, from the creation of the first permanent military medical service in 1899 to recruitment of physicians in recent missions.

And last, but not least, for the first time in 15 years, there will be no increase in CMA fees; they stand at $\$ 495$ annually.

Visit cmaj.ca for extensive news coverage of the annual meeting.

CMAJ 2014. DOI:10.1503/cmaj.109-4887 